\title{
What can available randomised controlled trials evaluating monitoring strategies tell us about the design and analysis of future trials?
}

\author{
Jacqueline Dinnes ${ }^{1 *}$, Jenny Hewison ${ }^{2}$, Doug Altman ${ }^{3}$, Jon Deeks ${ }^{1}$ \\ From Clinical Trials Methodology Conference 2011 \\ Bristol, UK. 4-5 October 2011
}

\section{Background}

Randomised controlled trials (RCTs) of monitoring regimes present unique challenges. Trials of monitoring evaluate a strategy, "a planned and organised system of repeated assessments and subsequent decisions about additional interventions, such as starting, stopping or modifying treatment" [1] all of which should be specified in advance, and ideally supported by previous research. The complexity of the intervention and consequent potential for "interactions between tests, repeated tests, test results and the decisions based on these results" [1] also necessitates large sample sizes in order to detect an effect on important patient outcomes.

\section{Objective}

To gain an insight into the extent to which monitoring schedules evaluated in RCTs have been informed by prior research and to highlight potential issues for design and analysis of future trials.

\section{Methods}

A review of available RCTs of monitoring regimes intended to allow earlier intervention in people with, or at high risk of, a condition that is likely to recur or progress was conducted. An electronic search of the CENTRAL database was carried out using the keywords (monitor* or serial* or surveill*) in the title or the same keywords in the abstract combined with (biomarker" or marker* or test* or examination* or measure*). RCTs comparing at least one formal monitoring strategy to no formal monitoring, to an alternative monitoring strategy, or to immediate treatment were included. Trials of

'Public Health, Epidemiology and Biostatistics, University of Birmingham, Edgbaston, Birmingham, B15 2TT, UK

Full list of author information is available at the end of the article monitoring where the main purpose was treatment titration, improvement in adherence to a treatment regimen, or evaluating ways of delivering monitoring were excluded. One author conducted the searches, screened the search results for relevant studies and carried out the data extraction. A narrative synthesis will be performed.

\section{Results}

Results will be presented for over 20 RCTs. In addition to information on trial quality, data will be presented on the extent to which the components of the monitoring schedule (testing frequency, threshold for intervention and actions consequent to crossing that threshold) have been specified. The MRC framework for evaluating complex interventions will be used to help inform the extraction of this information [2]. A further focus will be on the types of outcomes assessed by the trials and reporting of sample size calculations.

\section{Conclusions}

The review's results will be used to inform guidance regarding the future evaluation of monitoring regimes.

\section{Author details \\ ${ }^{1}$ Public Health, Epidemiology and Biostatistics, University of Birmingham, Edgbaston, Birmingham, B15 2TT, UK. '2Leeds Institute for Health Sciences, University of Leeds, Charles Thackrah Building, 101 Clarendon Road, Leeds, LS2 9LJ, UK. ${ }^{3}$ Centre for Statistics in Medicine, University of Oxford, Wolfson College Annexe, Linton Road, Oxford, OX2 6UD, UK.}

Published: 13 December 2011

\section{References}

1. Bossuyt PM: Evaluating the effectiveness and costs of monitoring. In Evidence-based medical monitoring. From principles to practice. Oxford: Blackwell Publishing;Glasziou PP, Irwig L, Aronson JK 2008:158-165. 
2. Craig P, Dieppe P, Macintyre S, Michie S, Nazareth I, Petticrew M: Developing and evaluating complex interventions: new guidance. London: Medical Research Council; 2008.

doi:10.1186/1745-6215-12-S1-A48

Cite this article as: Dinnes et al: What can available randomised controlled trials evaluating monitoring strategies tell us about the design and analysis of future trials? Trials 2011 12(Suppl 1):A48.

Submit your next manuscript to BioMed Central and take full advantage of:

- Convenient online submission

- Thorough peer review

- No space constraints or color figure charges

- Immediate publication on acceptance

- Inclusion in PubMed, CAS, Scopus and Google Scholar

- Research which is freely available for redistribution

Submit your manuscript at www.biomedcentral.com/submit
() Biomed Central 